\title{
Cost-Effectiveness Analysis of Different Management Strategies for Detection CIN2+ of Women with Atypical Squamous Cells of Undetermined Significance (ASC-US) Pap Smear in Thailand
}

\author{
Tanitra Tantitamit ${ }^{1 *}$, Wichai Termrungruanglert ${ }^{1}$, Shina Oranratanaphan ${ }^{1}$, \\ Somchai Niruthisard ${ }^{1}$, Patuou Tanbirojn ${ }^{1}$, Piyalamporn Havanond ${ }^{2}$
}

\begin{abstract}
Background: To identify the optimal cost effective strategy for the management of women having ASC-US who attended at King Chulalongkorn Memorial Hospital (KMCH). Design: An Economical Analysis based on a retrospective study. Subject: The women who were referred to the gynecological department due to screening result of ASC-US at King Chulalongkorn Memorial Hospital, a general and tertiary referral center in Bangkok Thailand, from Jan 2008 - Dec 2012. Materials and Methods: A decision tree-based was constructed to evaluate the cost effectiveness of three follow up strategies in the management of ASC-US results: repeat cytology, triage with HPV testing and immediate colposcopy. Each ASC-US woman made the decision of each strategy after receiving all details about this algorithm, advantages and disadvantages of each strategy from a doctor. The model compared the incremental costs per case of high-grade cervical intraepithelial neoplasia (CIN2+) detected as measured by incremental cost-effectiveness ratio (ICER). Results: From the provider's perspective, immediate colposcopy is the least costly strategy and also the most effective option among the three follow up strategies. Compared with HPV triage, repeat cytology triage is less costly than HPV triage, whereas the latter provides a more effective option at an incremental cost-effectiveness ratio (ICER) of 56,048 Baht per additional case of CIN 2+ detected. From the patient's perspective, the least costly and least effective is repeat cytology triage. Repeat colposcopy has an incremental cost-effectiveness (ICER) of 2,500 Baht per additional case of CIN2+ detected when compared to colposcopy. From the sensitivity analysis, immediate colposcopy triage is no longer cost effective when the cost exceeds 2,250 Baht or the cost of cytology is less than 50 Baht (1USD = 31.58 THB). Conclusions: In women with ASC-US cytology, colposcopy is more cost-effective than repeat cytology or triage with HPV testing for both provider and patient perspectives.
\end{abstract}

Keywords: ASC-US - cost effectiveness - PAP smear - colposcopy - HPV testing - ICER

Asian Pac J Cancer Prev, 16 (16), 6857-6862

\section{Introduction}

Cervical cancer is the second most common cancer in the world and the most common gynecological cancer in Thailand. In 2009, the prevalence and mortality rate were 24.5 and 12.8 cases per 100,000 per year $(\mathrm{WHO} /$ ICO Information Centre., 2010). Fortunately, the optimal strategy for screening and management precancerous lesion would decrease both morbidity and mortality of cervical cancer.

The most common cytological abnormality is atypical cells of undetermined significance (ASC-US), 2.8\% of all PAP smear results in US (Katki et al., 2013). It carries the risk of CIN2 $6.9 \%$, CIN3 $2.6 \%$ and cervical cancer $0.1 \%$ (Katki et al., 2013). Where as the incidence of ASCUS in Thailand is 0.6-1.75\% (Chichareon et al., 2002; Chichareon et al., 2005; Limpvanuspong et al., 2008), and $1.5 \%$ in our institution. It has a relatively high prevalence of high grade lesions from several previous studies in Thailand (10-18\%) (Chichareon et al., 2002; Chichareon et al., 2005; Kantathavorm et al., 2008; Limpvanuspong et al., 2008; Suntornlimsiri et al., 2010; Poomtavorn et al., 2011).

The optimal strategy for ASC-US triage should identify those women who require treatment and avoiding unnecessary procedures. The management of ASC-US is controversial. Clinical data from ALTS has demonstrated that two repeat cytology performed at 6 months interval, testing for HPV DNA and a single colposcopy are effective approaches to management the women with ASC-US (Wright et al., 2007).

Colposcopy with directed biopsy is a gold standard strategy for detection CIN. From several studies in Thailand revealed that the incidence of high-grade lesions detected from ASC-US was higher than other studies in Europe and US (Chichareon et al., 2002; Chichareon et 
al., 2005; Kantathavorm et al., 2008; Limpvanuspong et al., 2008; Suntornlimsiri et al., 2010; Poomtavorn et al., 2011; Katki et al., 2013) Concerning the severity and high prevalence of disease, some institutes refer every ASCUS women to colposcopy. However, not all hospitals in Thailand have a standard colposcopy services with well-trained physicians. There is a long waiting list for colposcopy in our institute.

The repeat cytology is commonly used as a follow up method because it is not expensive and easy to do. The sensitivity of repeat cytology is $75 \%$ (Yarandi eal., 2009). The disadvantages are time consuming, increasing anxiety, patient's discomfort, poor compliance and delaying management in high-grade lesion patients. The HPV triage is an accepted approach and has a higher accuracy than repeat cytology method (Arbyn et al., 2013). Approximately 40 percent of women with ASCUS Pap smear had a negative result for high risk HPV. Those patients can avoid an unnecessary colposcopy (Solomon et al., 2001). HR-HPV is a high sensitivity test and considered as the most cost-effectiveness strategy from several previous studies (Lytwyn et al., 2000; Kim et al., 2002; Kulasingam et al., 2006; Sheriff et al., 2007; Vanni et al., 2011).

Although HPV testing was a preferred method from previous economic studies, it may not an appropriate option in Thailand because of the difference in cost and detection rate. For this reason, we conduct this study to evaluate the most effectiveness and the most economical strategy for management of ASCUS women to detect the lesions of CIN 2 or greater.

\section{Materials and Methods}

\section{Study design}

This is an economical analysis study based on retrospective data reviewed from medical record of women with ASC-US cytology who attended at OPD at King Chulalongkorn Memorial Hospital (KCMH), a general and tertiary referral center in Bangkok Thailand, from Jan 2008 to Dec2012. We use the colposcopy with directed biopsy to detect CIN 2+ as a gold standard method. Primary screening was performed by using the conventional method. The results were reported based on Bethesda 2001 system. If there is any abnormal result, the patients will be called to see the gynecologists. They will receive the details about management algorithm, advantage and disadvantages of each strategy in order to make a decision by themselves.

Three treatment strategies consists of colposcopy arm, HPV testing (Hybrid Capture $2^{\circledR}$ High-Risk HPV DNA Test TM) and repeat conventional cytology sampling. Women in the immediate colposcopy arm were referred to colposcopy and biopsy, those in the HPV triage arm were referred to colposcopy if high-risk HPV types were detected and those in repeat cytology arm which follow up at 6 and 12 months were referred to colposcopy if a repeat abnormal result occurred.

\section{Cost data}

We conducted the analysis from both health care provider (hospital) and patient's perspective. The recent cost data in 2013 were used and expressed in Thai Baht. $(1 \mathrm{USD}=31.58 \mathrm{THB})$. We use only direct medical costs, which were provided by Center of Health Assurance at $\mathrm{KCMH}$. The unit costs consist of the material costs such as HPV test cost, physician assessment, cytopathological laboratory test and electricity cost. Capital cost and labor cost were also included. Indirect costs such as loss of productivity and transportation costs were assumed to have the same among patients.

\section{Clinical data and cost effectiveness analysis}

A decision tree was developed to predict the clinical management algorithm. Base case values used in the model were mainly based on data from a retrospective study from Jan 2008 to Dec 2012. Effectiveness was expressed as the number of CIN2+ cases detected by different methods. The results of cost-effectiveness analysis were represented by incremental cost-effectiveness ratios (ICERs) per detected CIN 2+ case.

ICER is calculated from this formula; ICER $=(\mathrm{C} 1-$ $\mathrm{C} 2) /(\mathrm{E} 1-\mathrm{E} 2)$

C1-C2 = additional cost of method 1 compare with method 2

E1-E2 = additional case of CIN2+ detected of method1 compare with method 2

\section{Results}

Clinical data, cost data and base case analysis

From retrospective data of women referred to gynecological investigation due to Pap smear screening result of ASC-US. The total number of ASCUS diagnosed women was 1,401, but only 1,117 women followed up at gynecologic clinic of KCMH. There were 391, 157 and 569 women decided to undergo immediate colposcopy,

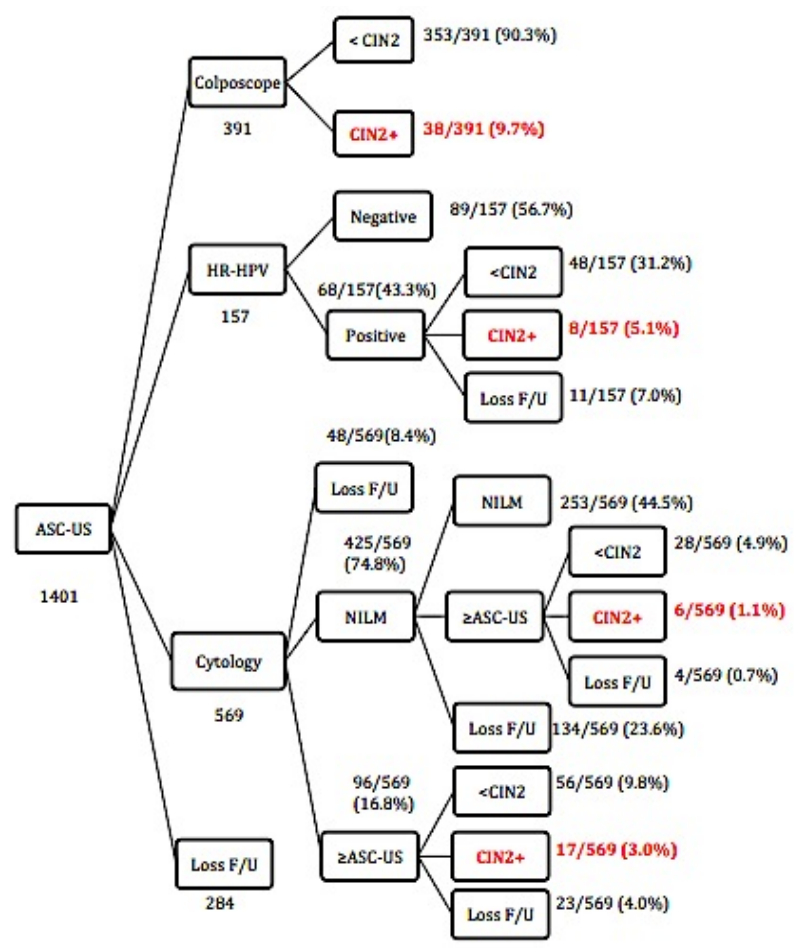

Figure 1.A Decision Tree of Three Follow-up Strategies 
Cost-Effectiveness of Strategies for Detection CIN2+ in Women with ASC-US Pap Smears in Thailand

HPV testing and repeat cytology respectively. All of these, 69 cases were proved to be CIN2+ through following pathological reports $(6.71 \%)$.

Figure 1 presents the CIN 2+ detected rate of each strategy. Colposcopy was the most effective method. The detected rate of CIN2+ cases was $9.7 \%$ whereas the detected rate of HPV-testing and PAP smear were 5.1\% and $4.1 \%$ respectively. Repeat cytology was the strategy that has the highest rate of noncompliance patients (13.1\%)

Directed medical cost used in both base case and sensitivity analysis was shown in Table 1

Table 2 presents the base-case effectiveness. Table 3 and Figure 2, present base-case incremental cost effectiveness result. In provider's perspective, both HPV testing and cytology triages were strongly dominated by colposcopy, that is, colposcopy constituted the least costly and most effective follow up strategy. Compare the repeat cytology with HPV triage; repeat cytology triage is less costly than HPV triage, whereas HPV triage provides more effective option at an incremental cost-effectiveness ratio (ICER) of 56,048 Baht per additional case of CIN $2+$ detected

In the patient's perspective, the least costly and least effective is repeat cytology triage. Repeat cytology has

Table 1. Direct Medical Costs Baseline Values and Ranges used in Sensitivity Analysis*

\begin{tabular}{|c|c|c|c|}
\hline \multirow{2}{*}{ STRATEGY } & \multicolumn{3}{|c|}{ COST (Baht) } \\
\cline { 2 - 3 } & \multicolumn{2}{|c|}{ Base case } & \multirow{2}{*}{ Ranges* } \\
\cline { 2 - 4 } & $\begin{array}{c}\text { Provider's } \\
\text { perspective }\end{array}$ & $\begin{array}{c}\text { Patient's } \\
\text { perspective }\end{array}$ & \\
\hline Colposcopy & 357 & 640 & $250-3200$ \\
\hline HPV testing & $1,121.58$ & $1,127.12$ & $300-2300$ \\
\hline Cytology & 561.1 & 500 & $150-1550$ \\
\hline
\end{tabular}

* Ranges used in sensitivity analysis for costs were obtained from a survey of laboratories from various government and private hospitals in Thailand

Table 2. Base case analysis of costs and outcome of evaluation of ASC-US

\begin{tabular}{|c|c|c|c|c|}
\hline \multirow{4}{*}{ Strategy } & Cost & CIN2+ & CIN2+ & \multirow{2}{*}{ C/E } \\
\cline { 2 - 4 } & (Baht) & $\begin{array}{c}\text { Detected } \\
\text { per } 100\end{array}$ & $\begin{array}{c}\text { Detected } \\
\text { per case }\end{array}$ & (Baht) \\
\hline Colposcopy & 357 & 9.7 & 0.097 & 3680 \\
\hline Cytology & 561.1 & 4.1 & 0.041 & 13685 \\
\hline HPV testing & $1,121.50$ & 5.1 & 0.051 & 21992 \\
\hline & CATIENT'S PERSPECTIVE & CIN2+ & CIN2+ & \multirow{2}{*}{ C/E } \\
\cline { 2 - 4 } Strategy & $($ Baht $)$ & $\begin{array}{c}\text { Detected } \\
\text { per } 100\end{array}$ & Detected \\
per case & \\
\hline Colposcopy & 640 & 9.7 & 0.097 & 6,598 \\
\hline Cytology & 500 & 4.1 & 0.041 & 12,195 \\
\hline HPV testing & $1,127.10$ & 5.1 & 0.051 & 22,100 \\
\hline
\end{tabular}

ASC-US: Atypical Squamous Cells of Undetermined Significance, CIN: Cervical intraepithelial neoplasia, C/E: Cost/Effectiveness an incremental cost-effectiveness (ICER) of 2,500 Baht per additional case of CIN2+ detected when compare to colposcopy.

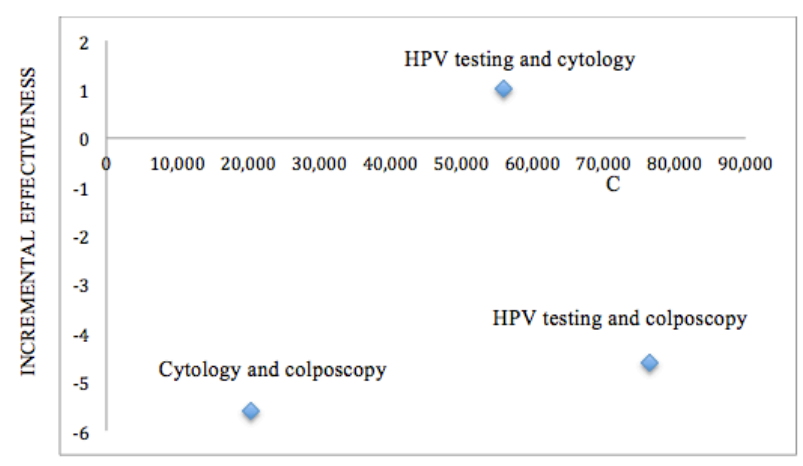

INCREMENTAL COST

Figure 2. Base-case Incremental Cost Effctiveness Results: Provider's Perspective

Table 3. Base-Case Incremental Cost Effectiveness Results

\begin{tabular}{|c|c|c|c|}
\hline \multicolumn{4}{|c|}{ PROVIDER'S PERSPECTIVE } \\
\hline Strategy & IC & IE & \multirow[b]{2}{*}{ ICER (Baht) } \\
\hline (cost-Baht) & (Baht) & $\begin{array}{c}\text { (CIN2+ detected } \\
\text { per case) }\end{array}$ & \\
\hline $\begin{array}{c}\text { Cytology } \\
(561.1) \text { and } \\
\text { Colposcopy } \\
(357.0)\end{array}$ & 204.1 & -0.056 & Dominated \\
\hline $\begin{array}{l}\text { HPV testing } \\
(1121.5) \text { and } \\
\text { Colposcopy } \\
(357.0)\end{array}$ & 764.58 & -0.046 & Dominated \\
\hline $\begin{array}{l}\text { HPV testing } \\
(1121.5) \text { and } \\
\text { Cytology } \\
(561.1)\end{array}$ & 560.48 & 0.01 & 56,048 \\
\hline \multicolumn{4}{|c|}{ PATIENT'S PERSPECTIVE } \\
\hline \multirow{2}{*}{$\begin{array}{c}\text { Strategy (cost- } \\
\text { Baht) }\end{array}$} & IC & IE & \multirow[b]{2}{*}{ ICER (Baht) } \\
\hline & (Baht) & $\begin{array}{c}\text { (CIN2+detected } \\
\text { per case })\end{array}$ & \\
\hline $\begin{array}{c}\text { Colposcopy } \\
\text { (640.0) and } \\
\text { Cytology } \\
(500.0)\end{array}$ & 140 & 0.056 & 2,500 \\
\hline $\begin{array}{l}\text { HPV testing } \\
(1121.1) \text { and } \\
\text { Colposcopy } \\
(640.0)\end{array}$ & 487.12 & -0.046 & Dominated \\
\hline $\begin{array}{l}\text { HPV testing } \\
(1127.1) \text { and } \\
\text { Cytology } \\
(500.0)\end{array}$ & 627.12 & 0.01 & 62,712 \\
\hline
\end{tabular}

ICER is calculated according to the following equation: $\mathrm{ICER}=(\mathrm{Cost}$ of screen strategy A - Cost of screening strategy B) / (Effectiveness of screen strategy A - Effectiveness of screening strategy B). Dominated strategies are those with higher costs and lower clinical efficiency than other strategies, IC: Incremental cost, IE: Incremental effectiveness, ICER: Incremental cost effectiveness ratio 


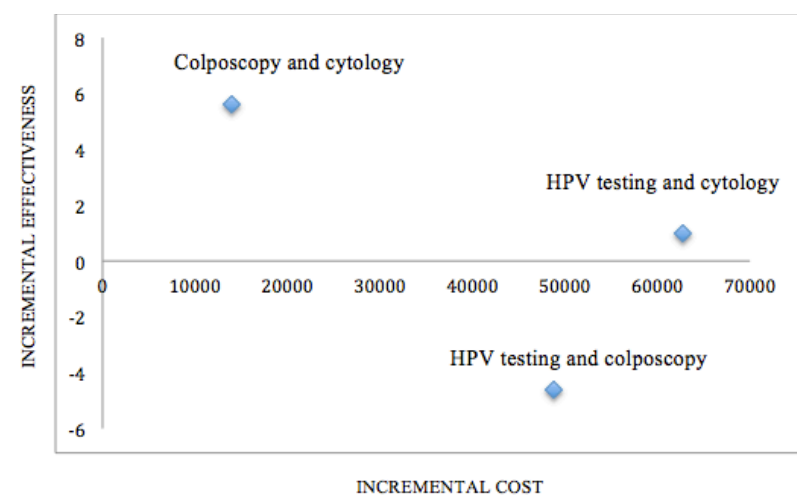

Figure 3. Base-case Incremental Cost Effctiveness Results: Provider's Perspective

Table 4. One Way Sensitivity Analysis of Colposcopy Costs

\begin{tabular}{|c|c|c|c|c|}
\hline $\begin{array}{l}\text { Plausible } \\
\text { colposcopy } \\
\text { cost (Baht) }\end{array}$ & \multicolumn{2}{|c|}{$\begin{array}{c}\text { Cost Range per } \\
\text { CIN2+ detected } \\
\text { (Baht) }\end{array}$} & $\begin{array}{c}\mathrm{C} / \mathrm{E} \\
\text { (Baht) }\end{array}$ & $\begin{array}{l}\text { ICER } \\
\text { (Baht) }\end{array}$ \\
\hline \multirow{3}{*}{250} & Colposcopy & 250 & 2,577 & \\
\hline & Cytology & 408.35 & 9,960 & Dominated \\
\hline & HPV testing & 985.25 & 18,789 & 56,790 \\
\hline \multirow{3}{*}{640} & Cytology & 500 & 12,195 & \\
\hline & Colposcopy & 640 & 6,598 & 2,500 \\
\hline & HPV testing & 1127.12 & 22,100 & Dominated \\
\hline \multirow{3}{*}{750} & Cytology & 525.85 & 12,825 & \\
\hline & Colposcopy & 750 & 7,732 & 4,002 \\
\hline & HPV testing & 1174.75 & 23,034 & Dominated \\
\hline \multirow{3}{*}{1250} & Cytology & 643.35 & 15,691 & \\
\hline & Colposcopy & 1250 & 12,886 & 10,833 \\
\hline & HPV testing & 1391.25 & 27,279 & Dominated \\
\hline \multirow{3}{*}{1750} & Cytology & 760.85 & 18,557 & \\
\hline & HPV testing & 1607.75 & 31,524 & 84,690 \\
\hline & Colposcopy & 1750 & 18,041 & 3,092 \\
\hline \multirow{3}{*}{2250} & Cytology & 878.35 & 21,423 & \\
\hline & HPV testing & 1824.25 & 35,769 & 94,590 \\
\hline & Colposcopy & 2250 & 23,195 & 9,255 \\
\hline \multirow{3}{*}{2750} & Cytology & 995.85 & 24,289 & \\
\hline & HPV testing & 2040.75 & 40,014 & 104,490 \\
\hline & Colposcopy & 2750 & 28,350 & 15,418 \\
\hline \multirow{3}{*}{3250} & Cytology & 1113.35 & 27,155 & \\
\hline & HPV testing & 2257.25 & 44,260 & 11,439 \\
\hline & Colposcopy & 3250 & 33,505 & 21,586 \\
\hline
\end{tabular}

*aC/E: Cost/Effectiveness, The follow up strategies are ordered by increasing costs. Incremental cost, CIN2+ cases detected (effectiveness) and incremental cost-effectiveness ratio (ICER) was calculated relative to the next less costly follow-up strategy

\section{Sensitivity analysis}

Table 4 presents the one-way sensitivity analysis of costs for follow up strategies. The model results were most sensitive to change in colposcopy costs. The cytology triage will become the most cost-effectiveness option when the cost of colposcopy exceeds 2,250 Baht or the
Table 5. One Way Sensitivity Analysis of Hpv Testing and Cytology Costs

\begin{tabular}{|c|c|c|c|c|}
\hline $\begin{array}{c}\text { Plausible } \\
\text { HPV } \\
\text { testing } \\
\text { cost }\end{array}$ & \multicolumn{2}{|c|}{$\begin{array}{c}\text { Cost Range per CIN2+ } \\
\text { detected (Baht) }\end{array}$} & $\begin{array}{c}\mathrm{C} / \mathrm{E} \\
\text { (Baht) }\end{array}$ & $\begin{array}{l}\text { ICER } \\
\text { (Baht) }\end{array}$ \\
\hline \multirow{3}{*}{300} & Cytology & 500 & 12,195 & \\
\hline & HPV testing & 577.12 & 11,316 & 7,712 \\
\hline & Colposcopy & 640 & 6,598 & 1,533 \\
\hline \multirow{3}{*}{800} & Cytology & 500 & 12,195 & \\
\hline & Colposcopy & 640 & 6,598 & 2,500 \\
\hline & HPV testing & 1077.12 & 2,112 & Dominated \\
\hline \multirow{3}{*}{1300} & Cytology & 500 & 12,195 & \\
\hline & Colposcopy & 640 & 6,598 & 2,500 \\
\hline & HPV testing & 1577.12 & 30,923 & Dominated \\
\hline \multirow{3}{*}{1800} & Cytology & 500 & 12,195 & \\
\hline & Colposcopy & 640 & 6,598 & 2,500 \\
\hline & HPV testing & 2077.12 & 40,727 & Dominated \\
\hline \multirow{3}{*}{2300} & Cytology & 500 & 12,195 & \\
\hline & Colposcopy & 640 & 6,598 & 2,500 \\
\hline & HPV testing & 2577.12 & 50,531 & Dominated \\
\hline \multirow{2}{*}{$\begin{array}{c}\text { Plausible } \\
\text { cytology } \\
\text { cost } \\
\text { (Baht) }\end{array}$} & \multirow{2}{*}{\multicolumn{2}{|c|}{$\begin{array}{c}\text { Cost Range per CIN2+ } \\
\text { detected (Baht) }\end{array}$}} & \multirow[b]{2}{*}{$\mathrm{C} / \mathrm{E}$} & ICER \\
\hline & & & & $\begin{array}{c}\text { (Baht/ } \\
\text { CIN2+ } \\
\text { detected) }\end{array}$ \\
\hline \multirow{3}{*}{50} & Cytology & 237.8 & 5,800 & \\
\hline & Colposcopy & 640 & 6,598 & 7,182 \\
\hline & HPV testing & 1127.12 & 22,100 & Dominated \\
\hline \multirow{3}{*}{550} & Colposcopy & 640 & 6,598 & \\
\hline & Cytology & 1111.8 & 27,117 & Dominated \\
\hline & HPV testing & 1127.12 & 22,100 & Dominated \\
\hline \multirow{3}{*}{1050} & Colposcopy & 640 & 6,598 & \\
\hline & Cytology & 1985.8 & 48,434 & Dominated \\
\hline & HPV testing & 1127.12 & 22,100 & Dominated \\
\hline \multirow{3}{*}{1550} & Colposcopy & 640 & 6,598 & \\
\hline & HPV testing & 1127.12 & 22,100 & Dominated \\
\hline & Cytology & 2859.8 & $69,7.51$ & Dominated \\
\hline
\end{tabular}

cost of cytology less than 50 Baht.

When vary HPV testing cost, HPV testing remains dominated by colposcopy. However, when the cost of HPV testing was less than 300 Baht, there was no longer a dominated alternative and provided more cost effective than cytology triage at ICER 7,712 Baht.

\section{Discussion}

There were 69 CIN2+ cases from 1,117 ASC-US results detected by all of the three strategies $(6.71 \%)$. This detection rate is lower than other previous studies in Thailand that show a prevalence of high grade CIN in women with ASC-US was 12-26\% (Chichareon et al., 2002; Kantathavorm et al., 2008; Limpvanuspong et 
al., 2008; Suntornlimsiri et al., 2010; Poomtavorn et al., 2011). This may result form different region and accuracy of pathologic interpretation in each institution.

The study of the effectiveness suggests that colposcopy triage was the most effective method, which can detect 9.7 CIN2+ cases per 100 women with ASC-US. The reason for lower detection rate in cytology and HPV testing triages might be interfered with loss to follow up women and there are a large number of women whom underwent an unnecessary colposcopy and biopsy in HPV testing (31.2\%) and cytology triages (14.7\%).

From laboratory survey from several hospitals in Thailand, colposcopy has the most various cost. It may be more or less costly than HPV testing. In our institution, unit cost of colposcopy is the least costly because the price in a government hospital has no additional doctor's fee as in a private hospital. Most cases were performed by the physicians trained in a fellowship program of the gynecologic oncologist at $\mathrm{KCMH}$. According to cost of colposcopy, it may affect the result of study causing difference from previous studies' results.

Regarding cost-effectiveness, the most costeffectiveness strategy in this study in both provider and patient's perspective is colposcopy. It is consistent with the study in Sweden (Ostensson et al., 2010), but different from several studies in high-income countries which present the HPV triage is an economically viable strategy for triage ASC-US cytology (Lytwyn et al., 2000; Kim et al., 2002; Kulasingam et al., 2006; Sheriff et al 2007; Vanni et al., 2011). However from the threshold analysis study in Brazil showed that if cost of HPV testing was more than twice cost of cytology, the optimal strategy would be immediate colposcopy that similar to our study (Vanni et al., 2011). In addition to the reason of unit cost, the strategies evaluated in others studies were different from our study. Liquid based cytology was always used as the method of routine screening. That might increase detected rate in HPV strategy.

From sensitivity analysis study, the most costeffectiveness strategy was no longer colposcopy when increasing costs of colposcopy to 2,250 Baht or decreasing costs of cytology to 50 Baht. Lower the costs of HPV testing are needed in order to be more cost effective follow up strategy, similar to study Sweden (Ostensson et al., 2010). If liquid based cytology was used in primary screening, HPV triage would become substantially less expensive and cost effective compared with other two triages.

The strengthen of this study is the first costeffectiveness analysis of strategies for management women diagnosed ASC-US smear result in Thailand which is a resource-limited country. The costs of colposcopy are varied especially between government and private hospital in Thailand. Therefore, we conducted the sensitivity analysis by changing the colposcopy cost which made it possible to explore in more depth in the uncertainty cost.

There are several limitations in this study. First, our study modeled an intermediate outcome (CIN2+) over a short time period. Therefore, may be unable to estimate the cost per year of life or quality - adjusted life year gained. Second, this study only estimated the detected rate of CIN2+ cases obtained from a retrospective study in the single institution that cannot represent the entire population in Thailand. Third, high rates of loss to follow up might interfere the effectiveness of cytology and HPV testing. Fourth, lack of information on the quality of life related to the different strategies may be considered. Although colposcopy was the most effective method, it might cause negative psychological effect associated with an examination. The HPV testing and cytology triages might cause anxiety because they need a period of time to follow up and do not completely avoid the unnecessary to perform colposcopy. Last, there are also other factors that may affect the effectiveness of each strategy such as the experience of physicians, the reliability and accuracy of laboratory and pathological interpretation which are difficult to access.

To clarify the accurate cost-effectiveness of each triage, future study should be a prospective study from multicenter in Thailand. It also would be valuable to obtain and compare QALYs of the women who diagnosed ASC-US smear results after performed different strategies. Currently, the follow up protocol was changed as ASCCP 2012; reflex HPV testing is preferred and extends the follow up period of cytology triage. Adjustment of the economic model is necessary to give better information for decision making in the future.

In conclusion, the results of the study may guide the physicians in counseling and management the women with ASC-US cytology for the optimal management in low -resource countries and may be benefit for health policies and resource management of the hospitals.

\section{References}

Arbyn M, Roelens J, Simoens C, et al (2013). Human papillomavirus testing versus repeat cytology for triage of minor cytological cervical lesions. Cochrane Database Syst Rev, 3, 8054.

Chichareon SB, Tocharoenvanich ST (2002). Situation analysis of atypical squamous cells of undetermined significance smears in Songklanagarind Hospital. J Obstet Gynaecol Res, 28, 269-73.

Chichareon SB, Tassee S, Wootipoom V, et al (2005). Situation analysis for management of abnormal Pap smears in the lower southern Thailand. Asian Pac J Cancer Prev, 6, 286-94.

Kantathavorn N, Kietpeerakool C, Suprasert P, et al (2008). Clinical relevance of atypical squamous cells of undetermined significance by the 2001 bethesda system: experience from a cervical cancer high incidence region. Asian Pac J Cancer Prev, 9, 785-8.

Katki HA, Schiffman M, Castle PE, et al (2013). Benchmarking CIN 3+ risk as the basis for incorporating HPV and Pap cotesting into cervical screening and management guidelines. J Low Genit Tract Dis, 17, 28-35.

Katki HA, Schiffman M, Castle PE, et al (2013). Five-year risks of CIN 3+ and cervical cancer among women who test Pap-negative but are HPV-positive. J Low Genit Tract Dis, 17, 56-63.

Kim JJ, Wright TC, Goldie SJ (2002). Cost-effectiveness of alternative triage strategies for atypical squamous cells of undetermined significance. JAMA, 287, 2382-90.

Kulasingam SL, Kim JJ, Lawrence WF, et al (2006). Costeffectiveness analysis based on the atypical squamous 


\section{Tanitra Tantitamit et al}

cells of undetermined significance/low-grade squamous intraepithelial lesion triage study (ALTS). J Natl Cancer Inst, 98, 92-100.

Limpvanuspong B, Tangjitgamol S, Manusirivithaya S, et al (2008). Prevalence of high grade squamous intraepithelial lesions (HSIL) and invasive cervical cancer in patients with atypical squamous cells of undetermined significance (ASCUS) from cervical pap smears. Southeast Asian J Trop Med Public Health, 39, 737-44.

Lytwyn A, Sellors JW, Mahony JB, et al (2000). Comparison of human papillomavirus DNA testing and repeat papanicolaou test in women with low-grade cervical cytologic abnormalities: a randomized trial. HPV Effectiveness in Lowgrade Paps (HELP) Study No. 1 Group. CMAJ, 163, 701-7.

Ostensson E, Froberg M, Hjerpe A, et al (2010). Economic analysis of human papillomavirus triage, repeat cytology, and immediate colposcopy in management of women with minor cytological abnormalities in Sweden. Acta Obstet Gynecol Scand, 89, 1316-25.

Poomtavorn Y, Suwannarurk K, Thaweekul Y, et al (2011). Risk factors for high-grade cervical intraepithelial neoplasia in patients with atypical squamous cells of undetermined significance (ASC-US) Papanicolaou smears. Asian Pac J Cancer Prev, 12, 235-8.

Sheriff SK, Petry KU, Ikenberg H, et al (2007). An economic analysis of human papillomavirus triage for the management of women with atypical and abnormal Pap smear results in Germany. Eur J Health Econ, 8, 153-60.

Solomon D, Schiffman M, Tarone R (2001). Comparison of three management strategies for patients with atypical squamous cells of undetermined significance: baseline results from a randomized trial. J Natl Cancer Inst, 93, 293-9.

Suntornlimsiri W (2010). Women in a region with high incidence of cervical cancer warrant immediate colposcopy for atypical squamous cells of undetermined significance on cervical cytology. J Med Assoc Thai, 93, 676-81.

Vanni T, Legood R, Franco EL, et al (2011). Economic evaluation of strategies for managing women with equivocal cytological results in Brazil. Int J Cancer, 129, 671-9.

WHO/ICO Information Centre on HPV and Cervical Cancer (2010). Human papillomavirus and related cancers in thailand. summary report 2010. [Date accessed].

Wright TC, Jr., Massad LS, Dunton CJ, et al (2007). 2006 consensus guidelines for the management of women with abnormal cervical screening tests. J Low Genit Tract Dis, 11, 201-22.

Yarandi F, Shojaei H, Eftekhar Z, et al (2009). Comparison of three management strategies for patients with atypical squamous cells of undetermined significance, after six months delay: a three-year experience in an Iranian university hospital. Aust NZ J Obstet Gynaecol, 49, 207-10. 